\title{
Persistence of wild rabbit (Oryctolagus cuniculus) latrines and its implication for monitoring programs
}

\author{
Carlos Rouco $^{\mathrm{a}, \mathrm{b}, *,}$, Rafael Villafuerte ${ }^{\mathrm{b}, \mathrm{c}}$, Juan Antonio Aguayo-Adán ${ }^{\mathrm{a}}$, \\ Daniel Carrasco-Expósito ${ }^{a}$, Silvia Íñigo-López ${ }^{\text {a }}$, Hajar Jeblaoui a , Julia Jiménez-Fernández ${ }^{\text {a }}$, \\ Juan Carlos Jiménez-Uceda ${ }^{a}$, Delia Limones-Ceballos ${ }^{a}$, María del Carmen López-Luengo ${ }^{\text {a }}$,

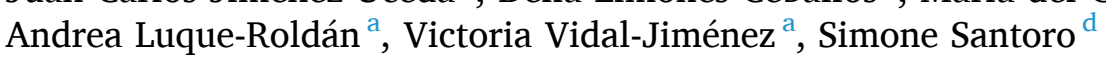 \\ a Área de Ecología, Departamento de Botánica, Ecología y Fisiología Vegetal, Universidad de Córdoba, Córdoba, Spain \\ ${ }^{\mathrm{b}}$ Sociedad, Ecología y Gestión del Medio Ambiente, UCO-IESA, Unidad Asociada al CSIC, Córdoba, Spain \\ ${ }^{\mathrm{c}}$ Instituto de Estudios Sociales Avanzados, IESA-CSIC, Córdoba, Spain \\ d Departamento de Ciencias Integradas, Facultad de Ciencias Experimentales, Universidad de Huelva, 21007, Huelva, Spain
}

\section{A R T I C L E I N F O}

\section{Keywords:}

Abundance index

Pellet's decay rate

Population abundance

Wildlife monitoring

\begin{abstract}
A B S T R A T
Counting latrines is a standard method to estimate European wild rabbits (Oryctolagus cuniculus) abundance. This method plays an important role in endangered predators' conservation programs in the Iberian Peninsula, especially in potential reintroduction areas for the Iberian lynx (Lynx pardinus). However, since the last halfcentury, rabbit populations have declined dramatically within their native range, mainly due to the effect of two viral diseases, which have caused even local extinctions of natural populations. Hence, we raise the question regarding how reliable the method of counting latrines may be in ensuring the abundance of rabbit populations after an event of sudden decline or even local extinction. To answer this question, we carry out a simple experiment where we set ten lines with rabbit latrines with two different sizes each (small and large) and simulated low- and high-abundant rabbit population scenarios on five latrine lines each, respectively. Then, we calculated the pellets decay rate and latrines persistence rate through monthly surveys. Our results showed that the daily persistence rate varied little among the different scenarios. However, generally, latrines do not persist long (78 days on average) regardless of the size of the latrines or rabbit population abundance. The longest time to extinction for pellets (c. 469 days, 97.5 quantile) was longer than the time until no more latrines were identified (c. 191 days, 97.5 quantile). We conclude that, although we did not consider other factors that could affect pellets decay, counting latrines seems to be sensible to a hypothetical dramatic decline event of a wild rabbit population. Therefore, if there is evidence of an epidemiological outbreak event, we suggest managers carry out latrines census at least between 140-220 days after an outbreak detection to reduce bias on the determination of rabbit abundance.
\end{abstract}

\section{Introduction}

European wild rabbits (Oryctolagus cuniculus) are social species, and they commonly used latrines as olfactory and visual signals (Ziege et al., 2016). Furthermore, latrines are a key element of maintenance behaviour in rabbits and a critical source of social and territorial information (Domínguez-Cebrían \& de Miguel, 2013). Due to their importance and to the costs associated with their deposition (Monclús, Arroyo, Valencia, \& Miguel, 2009), the establishment, use, and maintenance of latrines depend on the time and energy animals can effectively invest in their marking behaviour, and ultimately, on the size of their territory and their abundance (Ziege et al., 2016). Thus, counting rabbit latrines are frequently used as an indirect method to estimate wild rabbit populations abundance, not only within its native range (e.g. Delibes-Mateos, Ferreras, \& Villafuerte, 2008; Delibes-Mateos, Delibes, Ferreras, \& Villafuerte, 2008; Ferreira, Paupério, \& Alves, 2010; Guerrero-Casado, Carpio, Ruiz-Aizpurua, \& Tortosa, 2013; Virgós, Cabezas-Díaz, Malo, Lozano, \& López-Huertas, 2003) but elsewhere (e.g. Australia, Mutze, Cooke, Lethbridge, \& Jennigns, 2014). It also has been used to monitor populations abundance of other lagomorph species (e.g. Fowler \&

\footnotetext{
* Corresponding author at: Departamento de Botánica, Ecología y Fisiología Vegetal, Campus de Rabanales, Universidad de Córdoba, 14071, Córdoba, Spain.

E-mail address: crouco@uco.es (C. Rouco).
} 
Kissell, 2007; Rizo-Aguilar, Guerrero, Hidalgo-Mihart, \& González-Romero, 2015). In order to obtain a population abundance estimate, it is necessary to take into account the species defecation rate and the pellet persistence rate (Fernández-de-Simón, Díaz-Ruiz, Cirilli et al., 2011; Fernández-de-Simón, Díaz-Ruiz, Villafuerte, Delibes-Mateos, \& Ferreras, 2011; Plumptre \& Harris, 1995). Persistence can be expressed as the number of days for which a group of pellets persists (Hemami \& Dolman, 2005), and it has been frequently used in the literature (e.g. Palomares, 2001; Sanchez, Rachlow, Robinson, \& Johnson, 2009). Despite some controversies (Fernández-de-Simón, Díaz-Ruiz, Cirilli et al., 2011; Fernández-de-Simón, Díaz-Ruiz, Villafuerte et al., 2011; Guerrero-Casado et al., 2020), counting latrines is an easy and comomn method used for monitoring rabbit wild populations, especially in areas where rabbits occur at low densities and endangered Iberian predators remain, such as the Iberian lynx (Lynx pardinus) or the Iberian imperial eagle (Aquila adalberti). For example, there is even a minimum threshold of 20 latrines/ $\mathrm{km}$ to identify the areas of the minimum abundance of rabbits to identify potential reintroduction areas of Iberian lynxes in the conservation program of the species in the Iberian Peninsula (Iberlince, 2016).

On the other hand, the European wild rabbit is the staple prey of more than 30 native predators of the Iberian Peninsula (Delibes-Mateos, Delibes et al., 2008; Delibes-Mateos, Ferreras et al., 2008), where they are native (Monnerot et al., 1994). However, its wild populations have undergone a sharp decline during the last decades with a negative impact on both game-based economy and the conservation of threatened species that depend on rabbits (Delibes-Mateos, Ferreras, \& Villafuerte, 2009). Consequently, the European wild rabbit is considered an endangered species within its native range (Villafuerte \& Delibes-Mateos, 2019). Among the reason for such decline, prevail habitat loss, but above all the arrival of two viral diseases: myxomatosis in the 1950s and two different strains causative of the rabbit haemorrhagic disease (RHD) at the end of the 1980s and 2010, respectively (e.g., Delibes-Mateos et al., 2009; Rouco et al., 2018; Rouco, Abrantes, \& Delibes-Mateos, 2020). The impact of these diseases causes dramatic declines in rabbit populations, including the extinction of local populations (e.g., Villafuerte, Calvete, Blanco, \& Lucientes, 1995; Virgós et al., 2003). Both myxomatosis and RHD are endemic diseases (Abrantes, van der Loo, Le Pendu, \& Esteves, 2012; Villafuerte et al., 2017), and recurrent outbreaks occur every year, although with different severity.

For the conservation of endangered predators dependent on rabbits', it is relevant to evaluate how reliable the method of counting latrines may be in ensuring the abundance of rabbit populations after a severe disease outbreak. In other words, for how long may a latrine persists once the local population dramatically declined or completely disappeared? In this study, we designed a simple experiment to evaluate wild rabbit latrines' persistence in different scenarios and, hence, verify the reliability of such a method to estimate rabbit abundance when an unexpected dramatic decline event occurs.

\section{Material and methods}

\subsection{Study site}

The study site consisted of open pastureland nearby the Campus of Rabanales of the University of Cordoba, Spain (37 $54^{\prime} 58.22^{\prime \prime} \mathrm{N}$ 442'24.85” W). The study last from December 2017 till May 2018. These dates were selected based on the time of year when RHD (i.e. Lagovirus europaeus/GI.2) outbreaks often occur (Rouco et al., 2018). The climate is typically Mediterranean, with hot, dry summers and mild, wet winters. The average daily temperature during the study period was $11.8^{\circ} \mathrm{C}$ (ranging from 6.4 to $17.9^{\circ} \mathrm{C}$ ), and the average daily precipitation was $2.9 \mathrm{~mm}$. Before beginning the experiment, a rabbit census was carried out in order to confirm the absence of wild rabbits in the study site. We set a total of 49 plots (area: $0.5 \mathrm{~m}^{2}$ ) $25 \mathrm{~m}$ apart, covering $2.25 \mathrm{ha}$ to count pellets of rabbits. Additionally, whereas moving among plots, we search for the presence of rabbits' activity signs, such as rabbit scrapes, warrens, or latrines. Not a single pellet nor rabbits' activity signs were reordered.

\subsection{Experimental design}

A latrine is generally defined as a group of at least 20 pellets within an area of $200 \times 300 \mathrm{~mm}^{2}$ (Delibes-Mateos, Ferreras et al., 2008; Delibes-Mateos, Delibes et al., 2008; Virgós et al., 2003) equivalent to a pellet's density of 333.3 excrements $/ \mathrm{m}^{2}$. We set ten lines with artificial rabbit latrines $3 \mathrm{~m}$ apart each, and, on each line, two latrines were set, one small and another large with $0.1 \mathrm{~m}^{2}$ (Ø: $36 \mathrm{~cm}$ ) and $1 \mathrm{~m}^{2}$ (Ø: 113 $\mathrm{cm}$ ) of diameter, respectively (Fig. 1). Five lines simulated a low-abundant wild rabbit population scenario. Another five lines simulated a scenario with a high-abundant wild rabbit population. Latrines were set with a pool of fresh rabbit pellets ( $<24 \mathrm{~h}$ old) from 150 wild rabbits kept in semi-captivity conditions in the "Centro de Estudios de Lagomorfos Silvestres" located in the Campus of Rabanales of the University of Cordoba. Rabbits had a mixed diet of alfalfa hay and rabbit commercial food (Cuniunic, NANTA, SA). To create latrines for the different scenarios, we set latrines starting density of 600 and 1900 excrements $/ \mathrm{m}^{2}$ per latrine for low- and high-abundant wild rabbit population, respectively. Thus, for the latrines simulating a low-abundant scenario, we spread regularly through an area of $0.1 \mathrm{~m}^{2}$ and $1 \mathrm{~m}^{2}$ a total of 60 and 600 fresh rabbits pellets for small (scenario 1) and large (scenario 2) latrine size, respectively. Similarly, for a high-abundant scenario, we regularly spread a total of 190 and 1900 fresh rabbits pellets for small (scenario 3) and large (scenario 4) latrine size, respectively. In this sense, our experimental design was conservative since the simulated population that we considered as "low abundant" had a 3-fold starting density of pellets than the referenced one based on field studies in the Iberian Peninsula (Delibes-Mateos, Ferreras et al., 2008; Delibes-Mateos, Delibes et al., 2008; Virgós et al., 2003). Monthly pellet counts were carried out regularly to calculate pellets' density on each latrine to estimate both pellets' decay rate and the latrines' persistence. For that purpose, we counted the total amount of pellets found inside a $10 \mathrm{~cm}$ diameter plot. We randomly placed and counted 5 and 20 plots on each visit per each small and large latrine, respectively. Therefore, based on our sampling plot area, the pellets' threshold number per plot to consider a true latrine was 2.62 pellet$\mathrm{s} /$ plot. As expected, since no rabbits and ungulates inhabit the study area, no coprophagous invertebrates were spotted in the latrines during the study.

\subsection{Observed persistence rates from the experiment}

First, we calculated the pellets' persistence rate for each of the four scenarios considered in our experiment: (scenario 1) small plot in lowabundant population, (scenario 2) small plot in high-abundant population, (scenario 3) large plot in low-abundant population, (scenario 4) large plot in high-abundant population. Since latrines were relatively close, we assumed a roughly constant proportional decay of pellets through the study period. Our data proceed from a limited area with little heterogeneity in the environmental conditions (e.g., spatial and climate variation). Hence, the decay rate variation is likely to depend mainly on the experimental conditions than on environmental differences. As the exponential function can ever reach zero, we added one to each pellets' count. Using the exponential approximation, the number of pellets that decay during a particular interval may be expressed as a function of constant time decay $(\lambda)$ such as:

$\frac{d N}{d t}=-\lambda N$

In other words, the expected number of pellets at a given moment $\left(N_{\text {next }}\right)$ is a function of the number of pellets at the previous time $\left(N_{\text {prev }}\right)$ such as: 


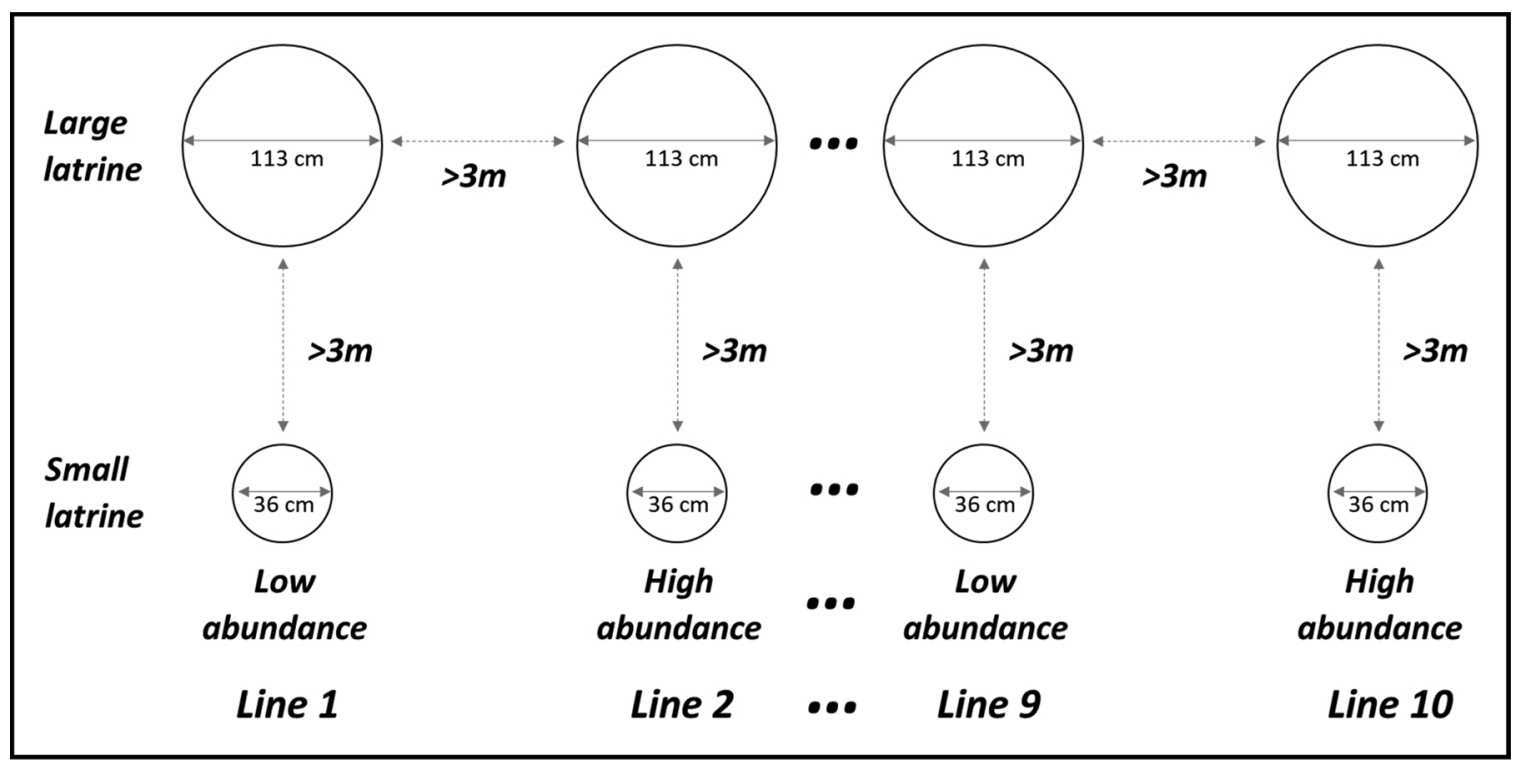

Fig. 1. Scheme of the experimental design showing four out of the ten lines of latrines set. Small $(\varnothing: 36 \mathrm{~cm})$ and large $(\varnothing: 113 \mathrm{~cm})$ circles indicate the location of small and large latrines. Odd (i.e. 1, 3, 5, 7 and 9) and even lines (i.e. 2, 4, 6, 8 and 10) simulated low- and high-abundant wild rabbit population scenarios.

$N_{\text {next }}=N_{\text {prev }} e^{-\lambda t}$

The persistence rate $(p)$ may be calculated as:

$p=1-\left(\ln \left(\frac{N_{\text {prev }}}{N_{\text {next }}}\right) / t\right)$

After calculating $p$ for each scenario and interval between field sessions, we calculated the average $\bar{p}$ of each scenario and its standard deviation $\bar{\sigma}$ (approximated by a truncated normal distribution, package truncnorm).

\subsection{Simulations of the latrines and pellets' extinction process}

Then, we simulated pellets' decay under four scenarios similar to those of the experiment. For each scenario, we simulated the persistence/decay of each pellet, all of them released on day 1, over 1000 days. The pellets' probability of persisting in the sample depended on a normal distribution with $\mu$ and $\sigma$ corresponding to the scenario-specific average persistence rate $(\bar{p})$ and standard deviation $(\bar{\sigma})$ calculated from real data. The number of initial pellets was the median number of pellets counted in each scenario. In the simulations, once an individual pellet disappeared, it remained in the same state $(0)$ for the rest of the time. Then, we calculated the number of pellets still present in the sample on each day since day 1 and recorded the number of days until there were no pellets left. We repeated this process 10,000 times, obtaining 10,000 estimated values of the days elapsed to pellets' extinction for each scenario. Then, we repeated the simulations to calculate, for each scenario, the number of days before less than 3 pellets were counted on a plot, which corresponds to the time to latrine's extinction. All the statistical analyses were performed in $\mathrm{R}$ version 4.0.2 (R Core Team, 2020).

\section{Results}

The daily persistence rate varied little among the four scenarios $(\bar{p}$ scenario1 $=0.9882 ; \bar{\sigma}_{\text {scenario } 1}=0.009 ; \bar{p}_{\text {scenario } 2}=0.9828 ; \bar{\sigma}_{\text {scenario } 2}=$ $0.0111 ; \bar{p}_{\text {scenario } 3}=0.9875 ; \bar{\sigma}_{\text {scenario } 3}=0.0098 ; \bar{p}_{\text {scenario } 4}=0.9834 ; \bar{\sigma}$ scenario $4=0.0111)$. By pooling all the simulations together, we found that the average (median) time after which no pellets were left in the sample was 196 days ( $2.5 \%$ quantile $=72$ days, 97.5 quantile $=423$ days). The estimates of the number of days before the pellets disappear are similar between the different scenarios showing a slight increase when the counting plots and pellets' density are larger (Fig. 2a; $2.5 \%$, $50 \%$ and 97.5 quantiles: scenario $1=51,153,387$ days; scenario $2=$ $83,166,336$ days; scenario $3=88,210,469$ days; scenario $4=150$, 245, 440 days).

By pooling all the scenarios, the average (median) time after which a latrine disappeared was 78 days $(2.5 \%$ quantile $=10$ days, 97.5 quantile $=191$ days). As expectable, similar to what we found for the time to pellets' extinction, the number of days to latrine's extinction followed a similar pattern between the different scenarios showing a slight increase when the latrines and pellets' density are larger (Fig. 2b; $2.5 \%, 50 \%$ and 97.5 quantiles: scenario $1=5,28,94$ days; scenario $2=41,77,138$ days; scenario $3=29,75,161$ days; scenario $4=99,147,218$ days).

\section{Discussion}

Our results revealed that wild rabbit latrines do not persist long when there is a lack of maintenance (c. 80 days pooling all scenarios together), regardless of the size of the latrines or rabbit population abundance. Our decay rates of pellets (i.e. $0.9828-0.9882$ ) were similar to those found in the literature (i.e. 0.9975 in Palomares, 2001, 0.9741-0.9943 in Fernández-de-Simón, Díaz-Ruiz, Cirilli et al., 2011; Fernández-de-Simón, Díaz-Ruiz, Villafuerte et al., 2011). As expected, the longest time to extinction for pellets (c. 469 days, 97.5 quantile) was longer than the time until no more latrines are identified (c. 191 days, 97.5 quantile). As mentioned above, these figures are conservative since our starting density of pellets for low abundance scenarios was high. Consequently, we could expect to find in the wild shortened periods to extinction for pellets and latrines.

We acknowledge that other factors that may affect pellets' decay rate, such as seasons, differences in habitat type, or diet (Cochran \& Stains, 1961; Fernández de Simón, Díaz-Ruiz, Villafuerte, Delibes-Mateos, Ferreras, 2011; Taylor \& Williams, 1956), were not considered in the current study. Rabbit pellet persistence can vary at different rates depending on the time of the year, the habitat, and the climatic conditions (Fernández de Simón, Díaz-Ruiz, Villafuerte et al., 2011). Due to our study area's homogeneity, we did not consider weather conditions as a driver of the decay rate. Nonetheless, meteorology, particularly rainfall, appears to increase rabbit pellets decay rate (Fernández de Simón, Díaz-Ruiz, Villafuerte et al., 2011; Iborra \& Lumaret, 1997), and consequently, the durability of latrines. We recorded average daily precipitation of $2.9 \mathrm{~mm}$ during our study period. 

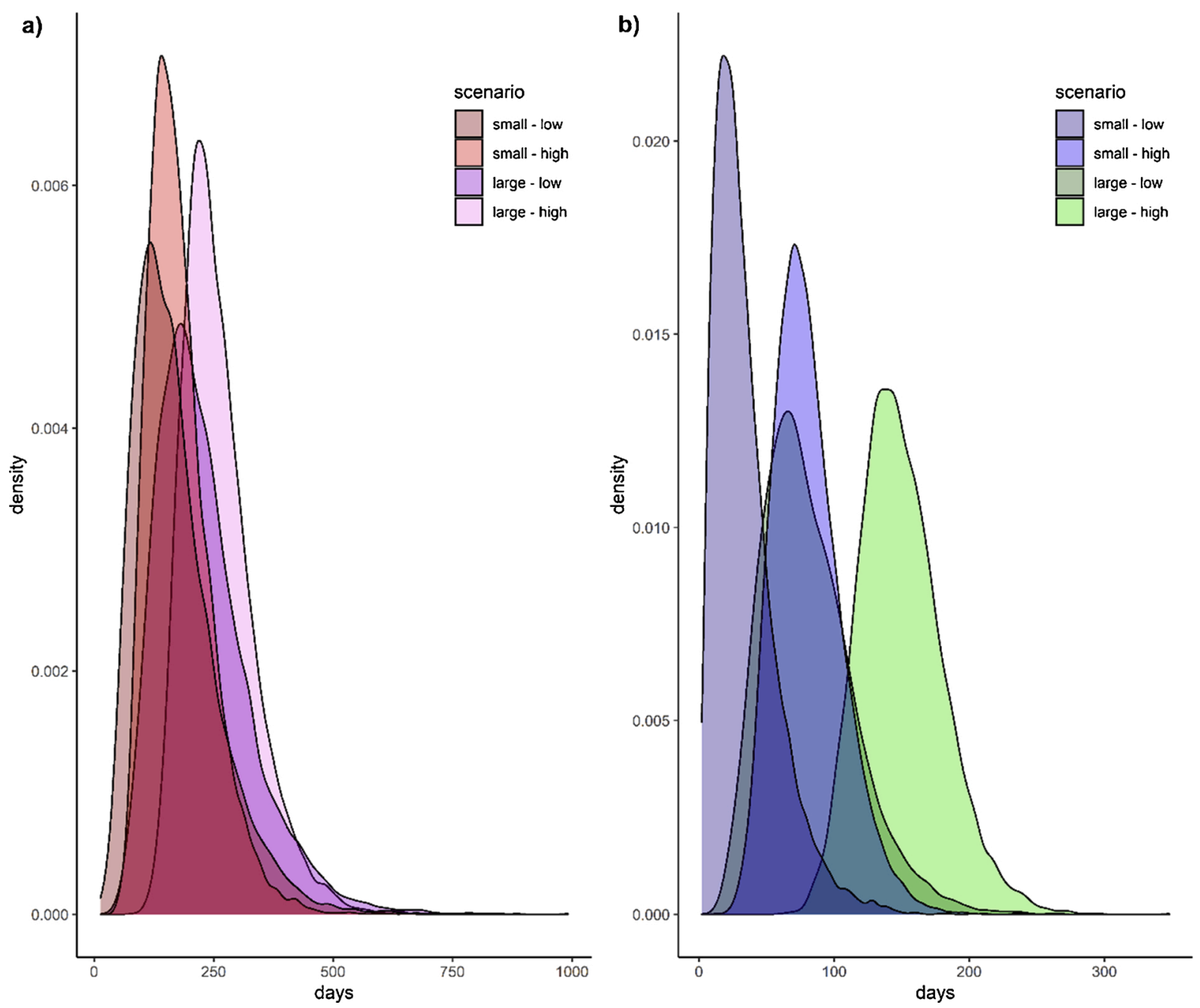

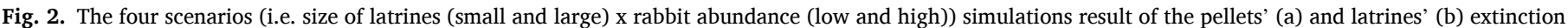

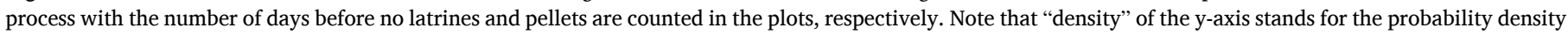
of the fitted standard distribution curves.

Therefore, in areas with lower precipitation rate, latrines are expected to last longer. On the other hand, a study with cottontails (Sylvilagus floridanus) revealed considerable differences in pellets decomposition rate depending on their composition (Cochran \& Stains, 1961). These authors found that pellets with lower decay rates were formed from commercial food (Cochran \& Stains, 1961), which would make our estimates even more conservatives if applied to our study. In such respect, suffice to mention the high diversity and abundance of dung beetles associated with the European rabbit in the Iberian Peninsula (Verdú \& Galante, 2004), which would increase rabbit pellets decay in the wild where present.

From a management perspective, latrines persistence seems to be relatively short-lived based on our low abundance scenarios (97.5 quantile $<140$ days). Our results revealed that the "counting latrines" method is sensitive to a sudden decline of a wild rabbit population. Therefore, if observers notice evidence of an epidemiological outbreak in a target area during a latrine census, we suggest managers and/or scientists carry out the latrine census at least 140 days later. However, if the original population was considered a high abundant one, this figure should increase to at least 220 days. Moreover, we also recommend, whenever possible, to estimate latrines persistence beforehand in those potential reintroduction areas for the Iberian lynx using a simple rabbit exclusion pen in located latrines. This way, managers will obtain reliable in-situ estimates.

\section{Declaration of Competing Interest}

We declare that there are no competing interests

\section{Acknowledgements}

This study was assisted by nine ungraduated students of Biology degree from the University of Córdoba by collaborating with the Department of Zoology (i.e. DCE, SIL, HJ, JJF, JCJU, DLC, MCLL, ALR, VVJ). Moreover, it was supported by a project granted by the Partnership for Research and Innovation in the Mediterranean Area (PRIMA) and funded by the Spanish Ministry of Science, Innovation and University (REF: PRIMAS2-11-PCI2019-103698).

\section{References}

Abrantes, J., van der Loo, W., Le Pendu, J., \& Esteves, P. J. (2012). Rabbit haemorrhagic disease (RHD) and rabbit haemorrhagic disease virus (RHDV): A review. Veterinary Research, 43, 12. https://doi.org/10.1186/1297-9716-43-12.

Cochran, G. A., \& Stains, H. J. (1961). Deposition and decomposition of fecal pellets by cottontails. The Journal of Wildlife Management, 25(4), 432-435.

Delibes-Mateos, M., Ferreras, P., \& Villafuerte, R. (2009). European rabbit population trends and associated factors: A review of the situation in the Iberian Peninsula. Mammal Review, 39, 124-140.

Delibes-Mateos, M., Delibes, M., Ferreras, P., \& Villafuerte, R. (2008). The key role of European rabbits in the conservation of the western Mediterranean basin hotspot. Conservation Biology, 22, 1106-1117. 
Delibes-Mateos, M., Ferreras, P., \& Villafuerte, R. (2008). Rabbit populations and game management: The situation after 15 years of rabbit haemorrhagic disease in centralsouthern Spain. Biodiversity and Conservation, 17, 559-574.

Domínguez-Cebrían, I., \& de Miguel, F. J. (2013). Selected factors influencing the spatia relationship between latrines and burrows in rabbits Oryctolagus cuniculus (L.) in a suburban area of Madrid (Spain). Polish Journal of Ecology, 61, 819-823.

Fernández-de-Simón, J., Díaz-Ruiz, F., Cirilli, F., Tortosa, F. S., Villafuerte, R., DelibesMateos, M., et al. (2011). Towards a standardized index of European rabbit abundance in Iberian Mediterranean habitats. European Journal of Wildlife Research, 57, 1091-1100.

Fernández-de-Simón, J., Díaz-Ruiz, F., Villafuerte, R., Delibes-Mateos, M., \& Ferreras, P. (2011). Assessing predictors of pellet persistence in European rabbits Oryctolagus cuniculus: Towards reliable population estimates from pellet counts. Wildlife Biology, 17, 317-325.

Ferreira, C., Paupério, J., \& Alves, P. C. (2010). The usefulness of field data and hunting statistics in the assessment of wild rabbit (Oryctolagus cuniculus) conservation status in Portugal. Wildlife Research, 37, 223-229.

Fowler, A., \& Kissell, R. E. (2007). Winter relative abundance and habitat associations of swamp rabbits in eastern Arkansas. Southeast Naturalist, 6, 247-258.

Guerrero-Casado, J., Carpio, A. J., Ruiz-Aizpurua, L., \& Tortosa, F. S. (2013). Restocking a keystone species in a biodiversity hotspot: recovering the European rabbit on a landscape scale. Journal for Nature Conservation, 21, 444-448.

Guerrero-Casado, J., Ström, H., Hilström, L., Prada, L. M., Carpio, A. J., et al. (2020). Assessment of the suitability of latrine counts as an indirect method by which to estimate the abundance of European rabbit populations at high and low abundance. European Journal of Wildlife Research, 66, 10.

Hemami, M. R., \& Dolman, P. M. (2005). The disappearanceof muntjac (Muntiacus reevesi) and roe deer (Capreoluscapreolus) pellet groups in a pine forest of lowlandEngland. European Journal of Wildlife Research, 51(1), 19-24.

Iberlince. (2016). Protocol for monitoring populations of wild rabbit. Life+IBERLINCE: Recovery of the historical distribution for Iberian Lynx (Lynx pardinus) in Spain and Portugal. (LIFE1ONAT/ES/570). Retrieved from http://www.iberlince.eu/index.ph p/eng/documents/documents-of-the-project/iberlince-protocols\#.YGHID68zZPY (Cited 1 April 2021).

Iborra, O. L., \& Lumaret, J. P. (1997). Validity limits of the pellet group counts in wild rabbit (Oryctolagus cuniculus). Mammalia, 61(2), 205-218.

Monclús, R., Arroyo, M., Valencia, A., \& Miguel, F. J. (2009). Red foxes (Vulpes vulpes) use rabbit (Oryctolagus cuniculus) scent marks as territorial marking sites. Journal of Ethology, 27, 153-155.

Monnerot, M., Vigne, J. D., Biju-Duval, C., Casane, D., Callou, C., Hardy, C., et al. (1994). Rabbit and man: Genetic and historic approach. Genetics Selection Evolution, 26, $167-182$.

Mutze, G., Cooke, B., Lethbridge, M., \& Jennigns, S. (2014). A rapid survey method for estimating population density of European rabbits living in native vegetation. The Rangeland Journal, 36, 239-247.
Palomares, F. (2001). Comparison of 3 methods to estimate rabbit abundance in a Mediterranean environment. Wildlife Society Bulletin, 29, 578-585.

Plumptre, A. J., \& Harris, S. (1995). Estimating the biomass oflarge mammalian herbivores in a tropical montaneforest: A method of faecal counting that avoids assuminga'steady state'system. Journal of Applied Ecology, 32(1), 111-120.

R Core Team. (2020). A language and environment for statistical computing. URL Available: Vienna, Austria: R Foundation for Statistical Computing https://www.Rproject.org/.

Rizo-Aguilar, A., Guerrero, J. A., Hidalgo-Mihart, M. G., \& González-Romero, A. (2015). Relationship between the abundance of the endangered volcano rabbit Romerolagus diazi and vegetation structure in the Sierra Chichinautzin mountain range, Mexico. Oryx, 49, 360-365.

Rouco, C., Abrantes, J., Serronha, A., Lopes, A. M., Maio, E., Magalhães, M. J., et al. (2018). Epidemiology of RHDV2 (Lagovirus europaeus/GI.2) in free living wild European rabbits in Portugal. Transboundary and Emerging Diseases, 65(2), e373-e382.

Rouco, C., Abrantes, J., \& Delibes-Mateos, M. (2020). Lessons from viruses that affect lagomorphs. Science, 369(6502), 386.

Sanchez, D. M., Rachlow, J. L., Robinson, A. P., \& Johnson, T. R. (2009). Survey indicators for pigmy rabbits: Temporaltrends of burrow systems and pellets. Western NorthAmerican Naturalist, 69(4), 426-436.

Taylor, R. R., \& Williams, R. M. (1956). The use of pellet counts for estimating the density of populations of the wild rabbit, Oryctolagus cuniculus (L.). New Zealand Journal of Science and Technology Section B, 38(3), 236-256.

Verdú, J. R., \& Galante, E. (2004). Behavioural and morphological adaptations for a lowquality resource in semi-arid environments: Dung beetles (Coleoptera, Scarabaeoidea) associated with the European rabbit (Oryctolagus cuniculus L.). Journal of Natural History, 38(6), 705-715.

Villafuerte, R., \& Delibes-Mateos, M. (2019). Oryctolagus cuniculus. The IUCN red list of threatened species 2019. https://doi.org/10.2305/IUCN.UK.2019-3.RLTS. T41291A170619657.en. e.T41291A170619657.

Villafuerte, R., Calvete, C., Blanco, J. C., \& Lucientes, J. (1995). Incidence of viral hemorrhagic disease in wild rabbit populations in Spain. Mammalia, 59, 651-659.

Villafuerte, R., Ramírez, E., Castro, F., Parra, F., Recuerda, P., Cotilla, I., et al. (2017) Large-scale assessment of myxomatosis prevalence in European wild rabbits (Oryctolagus cuniculus) 60 years after first outbreak in Spain. Research in Veterinary Science, 114, 281-286.

Virgós, E., Cabezas-Díaz, S., Malo, A., Lozano, J., \& López-Huertas, D. (2003). Factors shaping European rabbit abundance in continuous and fragmented populations of central Spain. Acta Theriologica, 48, 113-122.

Ziege, M., Bierbach, D., Bischoff, S., Brandt, A. L., Brix, M., Greshake, B., et al. (2016). Importance of latrine communication in European rabbits shifts along a rural-to-urban gradient. BMC Ecology, 16, 29. 